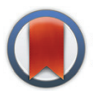

CrossMark \& click for updates

Cite this: Inorg. Chem. Front., 2015, 2, 584

DOI: 10.1039/c5qi90015h

rsc.li/frontiers-inorganic

\section{Correction: Organic-inorganic halide perovskite based solar cells - revolutionary progress in photovoltaics}

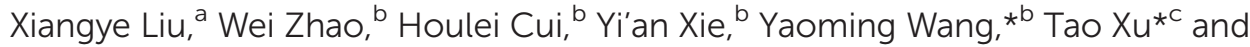
Fuqiang Huang*a

Correction for 'Organic-inorganic halide perovskite based solar cells - revolutionary progress in photovoltaics' by Xiangye Liu, et al., Inorg. Chem. Front., 2015, 2, 315-335.

The authors regret that the wrong Fig. 1 was included in the manuscript. The correct Fig. 1 is given below.
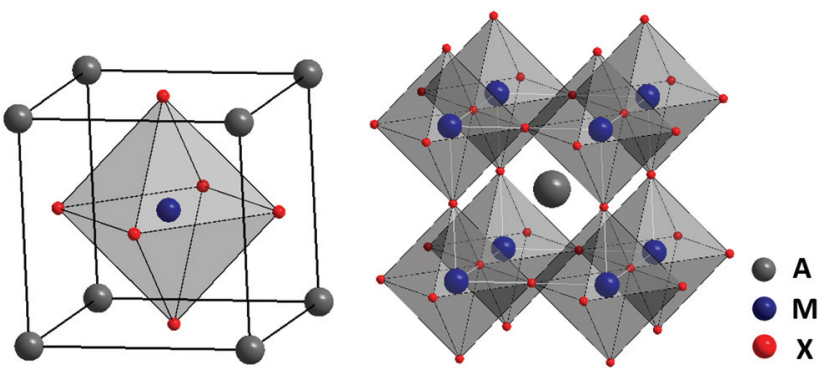

Fig. 1 Crystal structure of cubic perovskite of general formula $A B X_{3}$

The Royal Society of Chemistry apologises for these errors and any consequent inconvenience to authors and readers.

\footnotetext{
${ }^{a}$ Beijing National Laboratory for Molecular Sciences and State Key Laboratory of Rare Earth Materials Chemistry and Applications, College of Chemistry, Peking University, Beijing 100871, P.R. China. E-mail: huangfq@pku.edu.cn; Fax: (+86)10-62758225

${ }^{b}$ CAS Key Laboratory of Materials for Energy Conversion, Shanghai Institute of Ceramics, Chinese Academy of Sciences, Shanghai 200050, P.R. China.

E-mail: wangyaoming@mail.sic.ac.cn

${ }^{c}$ Department of Chemistry and Biochemistry, Northern Illinois University, DeKalb, Illinois 60115, USA. E-mail: txu@niu.edu
} 